\title{
Human Autologous In Vitro Models of Glioma Immunogene Therapy Using B7-2, GM-CSF, and IL12
}

\author{
Ian F. Parney, Maxine A. Farr-Jones, Kevin Kane, Lung-Ji Chang, \\ Kenneth C. Petruk
}

\begin{abstract}
Background: Cancer immunogene therapy is based on vaccination with radiated, autologous tumor cells transduced with immunostimulatory genes. To help determine an optimal glioma immunogene therapy strategy, we stimulated lymphocytes with autologous human glioma cells transduced with B7-2 (CD86), granulocyte-macrophage colony-stimulating factor (GM-CSF), and/or interleukin-12 (IL12). Methods: A human glioma-derived cell culture (Ed147.BT) was transduced with B7-2, GM-CSF, and/or IL12 using retroviral vectors. Autologous peripheral blood mononuclear cells (PBMC) were co-cultured with irradiated gene-transduced tumor alone or a combination of radiated wild type and gene-transduced cells. Peripheral blood mononuclear cells proliferation was determined by serial cell counts. Peripheral blood mononuclear cells phenotype was assessed by flow cytometry for CD4, CD8, and CD16. Anti-tumor cytotoxicity was determined by chromium-51 $\left({ }^{51} \mathrm{Cr}\right)$ release assay. Results: Peripheral blood mononuclear cells cell numbers all decreased during primary stimulation but tumor cells expressing B7-2 or GM-CSF consistently caused secondary proliferation. Tumors expressing B7-2 and GM-CSF or B7-2, GM-CSF, and IL12 consistently increased PBMC CD8+ (cytotoxic T) and $\mathrm{CD} 16+$ (natural killer) percentages. Interestingly, anti-tumor cytotoxicity only exceeded that of PBMC stimulated with wild type tumor alone when peripheral blood mononuclear cells were stimulated with both wild type tumor and B7-2/GM-CSF- (but not IL12) transduced cells. Conclusions: PBMC proliferation and phenotype is altered as expected by exposure to immunostimulatory genetransduced tumor. However, transduced tumor cells alone do not stimulate greater anti-tumor cytotoxicity than wild type tumor. Only B7-2/GM-CSF-transduced cells combined with wild type produced increased cytotoxicity. This may reflect selection of tumor subclones with limited antigenic spectra during retrovirus-mediated gene transfer.
\end{abstract}

RÉSUMÉ: Modèles autologues humains in vitro de thérapie immunogène pour le gliome au moyen de B7-2, GM-CSF et IL12. Introduction: La thérapie immunogène dans le traitement du cancer est basée sur la vaccination au moyen de cellules tumorales autologues irradiées et transfectée avec des gènes immunostimulants. Nous avons stimulé des lymphocytes au moyen de cellules de gliome humain autologue transfectées avec B7-2, le facteur de croissance des colonies de granulocytes-macrophages (GM-CSF) et/ou l'interleukine-12 (IL12) afin de définir une stratégie optimale de thérapie immunogène du gliome. Méthodes: Une culture de cellules de gliome humain (Ed147.BT) a été transfectée avec B7-2, GM-CSF et/ou IL12 au moyen de vecteurs rétroviraux. Des monocytes provenant de sang périphérique autologue (MSP) ont été co-cultivés seulement avec des cellules transfectées irradiées ou avec une combinaison de cellules de type sauvage irradiées et de cellules transfectées. La prolifération des monocytes du sang périphérique était déterminée par des décomptes cellulaires sériés. Le phénotype des monocytes du sang périphérique était évalué par cytométrie de flux pour CD4, CD8 et CD16. La cytotoxicité anti-tumorale était déterminée par le test de libération du chrome-51. Résultats: Le décompte des monocytes du sang périphérique a diminué pendant la stimulation primaire, mais les cellules tumorales exprimant B7-2 ou GM-CSF ont invariablement causé une prolifération secondaire. Les tumeurs exprimant B7-2 et GM-CSF ou B7-2, GM-CSF et IL12 ont invariablement augmenté le pourcentage des MSP CD8+ (T cytotoxiques) et CD16+ (tueurs naturels). Il est intéressant de noter que la cytotoxicité antitumorale était supérieurs à celle des MSP stimulés seulement par la tumeur de type sauvage quand les MSP étaient stimulés par la tumeur de type sauvage et les cellules transfectées avec B7-2/GM-CSF, mais pas avec IL12. Conclusions: Tel que prévu, la prolifération et le phénotype des MSP sont modifiés par l'exposition à des cellules tumorales transfectées avec des gènes immunostimulants. Cependant, les cellules tumorales transfectées seules ne stimulent pas une cytotoxicité antitumorale supérieure à celle de la tumeur de type sauvage. Seulement les cellules transfectées avec B7-2/GM-CSF combinées aux cellules de type sauvage ont provoqué une augmentation de la cytotoxicité, ce qui reflète possiblement une sélection de sous-clones tumoraux possédant un spectre antigénique limité pendant le transfert génique médié par le rétrovirus.

Can. J. Neurol. Sci. 2002; 29: 267-275

Common primary central nervous system tumors such as glioblastoma multiforme and other malignant gliomas continue to be associated with a dismal prognosis despite advances in diagnosis and therapy. ${ }^{1,2}$ Mean survival from the time of diagnosis is less than one year in most cases. This has spurred investigation of new treatment modalities such as immunogene
From the Divisions of Neurosurgery (IFP, MAF-J, KCP), Department of Surgery and Department of Medical Microbiology and Immunology (KK, L-JC), University of Alberta, Edmonton, Alberta, Canada

ReCeived OCtOBER 17, 2001. Accepted in final form February 19, 2002. Reprint requests to: I.F. Parney or K.C. Petruk, Division of Neurosurgery, Department of Surgery, 2D1.02 W.C. Mackenzie Health Sciences Center, University of Alberta, Edmonton, Alberta, Canada T6G 2R7 
therapy. This promising experimental strategy is based on genetically modifying patients' tumor cells in vitro to increase their immunogenicity. These cells are radiated to attenuate further cell division, then returned to patients as a subcutaneous vaccine. ${ }^{3}$ It is hoped that this will stimulate effective anti-tumor immune responses that will eradicate remaining tumor cells in the central nervous system.

Many different ways to modify glioma cells are possible in immunogene therapy. ${ }^{4,5}$ It is known that human gliomas secrete molecules such as transforming growth factor- $\beta 2$ (TGF-B2) $)^{6-8}$ and prostaglandin $\mathrm{E}_{2}$ (PGE2) ( $^{9,10}$ that inhibit lymphocyte proliferation. In addition, they secrete cytokines such as interleukin-6 (IL6), ${ }^{5,11}$ that shift immune responses toward humoral $\left(\mathrm{T}_{\mathrm{H}} 2\right)$ pathways that are less likely to be effective against solid tumors than cell mediated $\left(\mathrm{T}_{\mathrm{H}} 1\right)$ responses. Gliomas are also known to secrete large amounts of vascular endothelial growth factor (VEGF) which, in addition to promoting tumor angiogenesis, can be immunosuppressive by decreasing antigen presentation through inhibited dendritic cell maturation. ${ }^{12-14}$ Blocking expression of some of these immunosuppressive genes may be one way to stimulate anti-glioma immunity. For example, Fakhrai et $\mathrm{al}^{15}$ have reported complete eradication of intracranial rodent gliosarcomas after vaccination with irradiated syngeneic tumor cells transfected with a vector expressing antisense RNA directed against TGF-B2.

In addition to inhibiting expression of immunosuppressive cytokines, it may be possible to stimulate anti-tumor immunity by transferring immunostimulatory genes to tumor cells. ${ }^{5}$ In a seminal study, Dranoff et $\mathrm{al}^{16}$ found that vaccination with tumor cells transduced granulocyte-macrophage colony-stimulating factor (GM-CSF) resulted in potent, specific, and long lasting anti-tumor immunity in several rodent tumor models. In an extension of this work, Sampson et $\mathrm{al}^{17}$ and $\mathrm{Yu}$ et $\mathrm{al}^{18}$ demonstrated that vaccination with syngeneic GM-CSFtransduced tumor cells inhibited growth of intracranial rodent melanomas.

In our own laboratory, we have been investigating proinflammatory gene transfer for glioma immunogene therapy, ${ }^{5,19-21}$ focussing on three genes: GM-CSF, interleukin-12 (IL12), and B7-2 (CD86). As mentioned, GM-CSF has been effective in several rodent tumor immunogene therapy models. This may reflect its ability to stimulate antigen presenting cells. ${ }^{22-25}$ Interleukin-12 is a proinflammatory cytokine that shifts immune responses to $T_{H} 1$ (cellular) pathways and stimulates natural killer (NK) lymphocytes. ${ }^{26,27}$ This makes it very attractive for stimulating anti-tumor immunity. ${ }^{28} \mathrm{~B} 7-2$ is a $\mathrm{T}$ cell costimulatory molecule. Such costimulatory molecules are required in addition to antigen presentation in the context of a major histocompatibility complex for complete $\mathrm{T}$ lymphocyte activation. ${ }^{29-34}$ Costimulatory molecule gene transfer is another potential pathway to induce anti-tumor immunity. ${ }^{35,36}$

Many brain tumor immunogene therapy studies to date have relied on rodent tumor models such as 9L gliosarcoma, C6 glioma, or B16 melanoma. ${ }^{15,17,18,37,38}$ However, these models have many features of sarcomas that bring into question their relevance to human gliomas. ${ }^{39,40}$ In our laboratory, we have focussed on human glioma models. ${ }^{19,41}$ This has been facilitated by the development of a highly efficient technique for culturing human glioma cells from operative specimens. ${ }^{42}$
We have previously demonstrated that B7-2, GM-CSF, and IL12 genes can be efficiently transferred to early passage brain tumor cultures using our retroviral gene therapy vectors. ${ }^{20}$ Irradiation at a dose (200 Gy) that completely inhibited cell division did not appear to affect transferred gene expression. We have also shown that vaccination with irradiated glioma cells expressing B7-2 and GM-CSF completely inhibited the growth of pre-established tumors in a novel human glioma/allogeneic human lymphocyte/severe combined immunodeficiency mouse model. ${ }^{19}$ This study was the first of its kind to examine immunogene therapy in an in vivo human glioma/human lymphocyte system. However, the gliomas in this model were derived from an immortalized human glioma cell line but the lymphocytes were derived from healthy unrelated donors. Therefore, although the results of this study were very promising, its allogeneic nature leads to some caution regarding its validity.

To answer the question of whether similar results would be seen in an autologous human glioma/lymphocyte system, lymphocytes in the present study were stimulated in vitro with autologous glioma cells transduced with GM-CSF, B7-2, and/or IL12. Lymphocyte proliferation, cell surface markers, and cytotoxic activity vs. glioma were measured as markers of antitumor activity. This also allowed examination of synergy between cells transduced with various combinations of these genes.

\section{METHODS}

\section{Cell Culture}

Ed147.BT cell culture was derived from a 52-year-old male harboring a glioblastoma multiforme tumor. These were processed using previously described techniques. ${ }^{42}$ Briefly, fresh surgical tumor specimen was minced into small $(1-2 \mathrm{~mm})$ pieces then subjected to partial enzyme digestion with pronase, DNase, and collagenase. The resulting slurry was filtered through a tissue culture sieve then centrifuged on a density gradient (Ficoll) to remove contaminating mesenchymal cells such as fibroblasts. Cells were cultured at $37^{\circ} \mathrm{C}, 5 \% \mathrm{CO}_{2}$ in Dulbecco's modified Eagle's/F12 media (DMEM/F12) supplemented with $10 \%$ fetal bovine serum, L-glutamine, and penicillin/streptomycin.

\section{Cloning B7-2, GM-CSF, and IL12 Gene Transfer Vectors}

cDNA's for B7-2, GM-CSF, IL12A, and IL12B were generated by reverse transcriptase polymerase chain reaction (rtPCR) using primers designed from previously published gene sequences available on the NCBI gene bank. These were ligated into pLSN, a replication-incompetent retroviral gene therapy vector derived from the Maloney leukemia virus. ${ }^{43}$ This yielded replication-incompetent retroviral gene therapy vectors encoding B7-2 (pLSNB70), GM-CSF (pLSNGM1), IL12A and IL12B (pLSNIL12), or B7-2 and GM-CSF (pLSNBG9). Bicistronic vectors that contained two genes under the control of a single promotor region (pLSNIL12, pLSNBG9) linked these genes with an internal ribosome entry site (IRES) derived from the encephalomyocarditis virus genome (Novagen). In addition to the therapeutic genes (all under the control of an LTR promotor), these vectors also contain a neomycin-resistance gene under the 


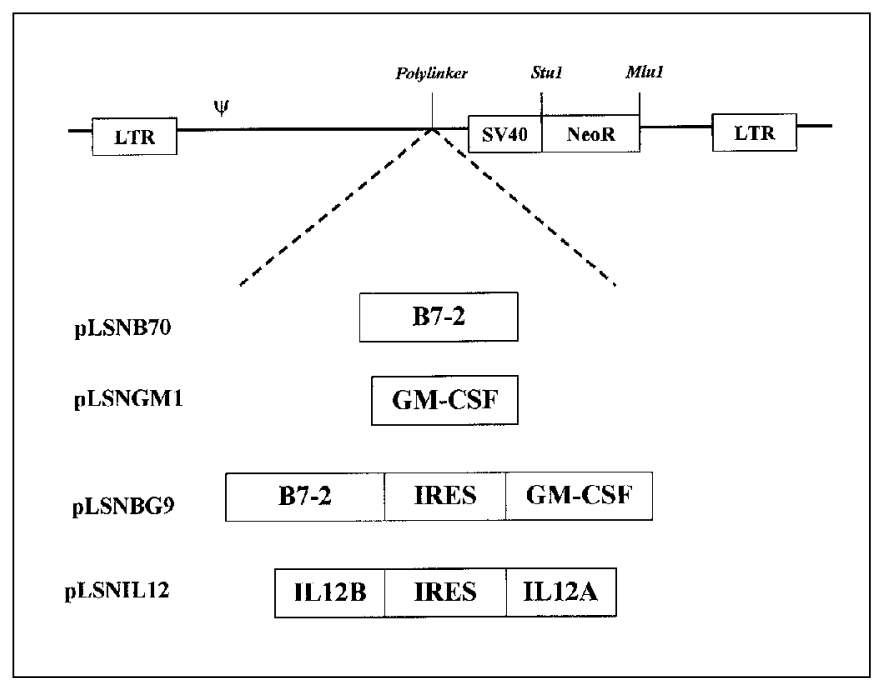

Figure 1: Schematic plasmid map showing the $p L S N$ retroviral backbone with inserts at the polylinker site encoding B7-2,GM-CSF, B72/GM-CSF, and IL12B/IL12A. All therapeutic genes inserted at the polylinker site are under the control of the LTR promoter region. In all vectors, a neomycin-resistance gene (NeoR) is under the control of an SV40 promoter. All vectors contain a packaging signal $(\psi)$ but lack genes encoding retroviral coat proteins (gag, pol, env). This renders them replication-incompetent.

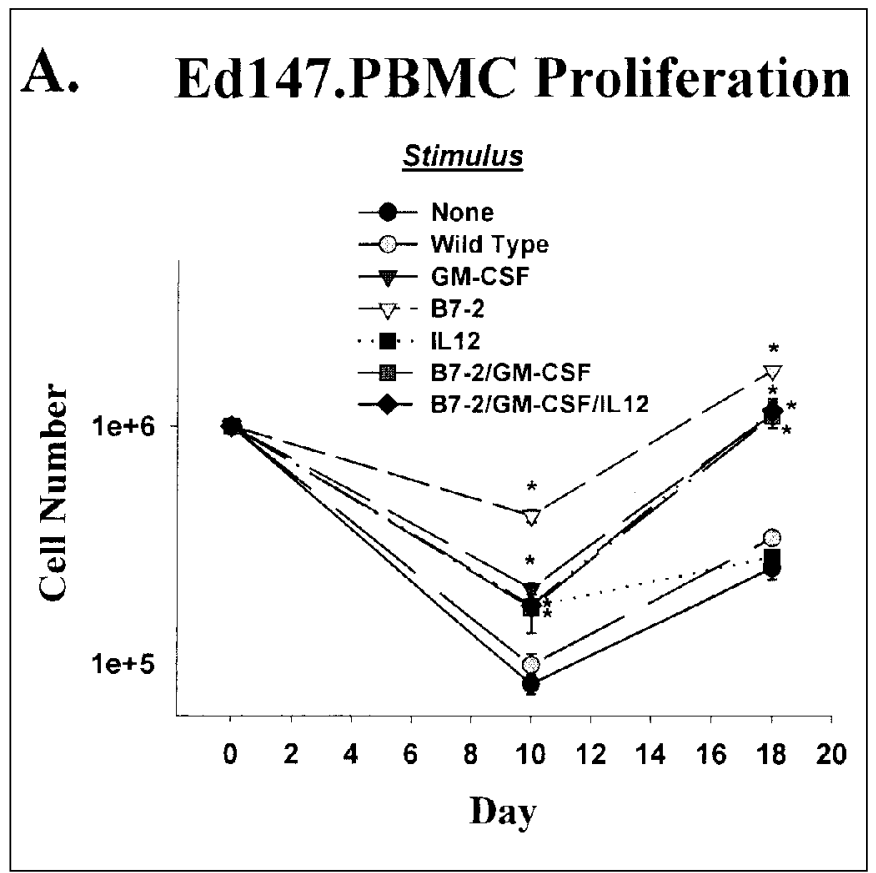

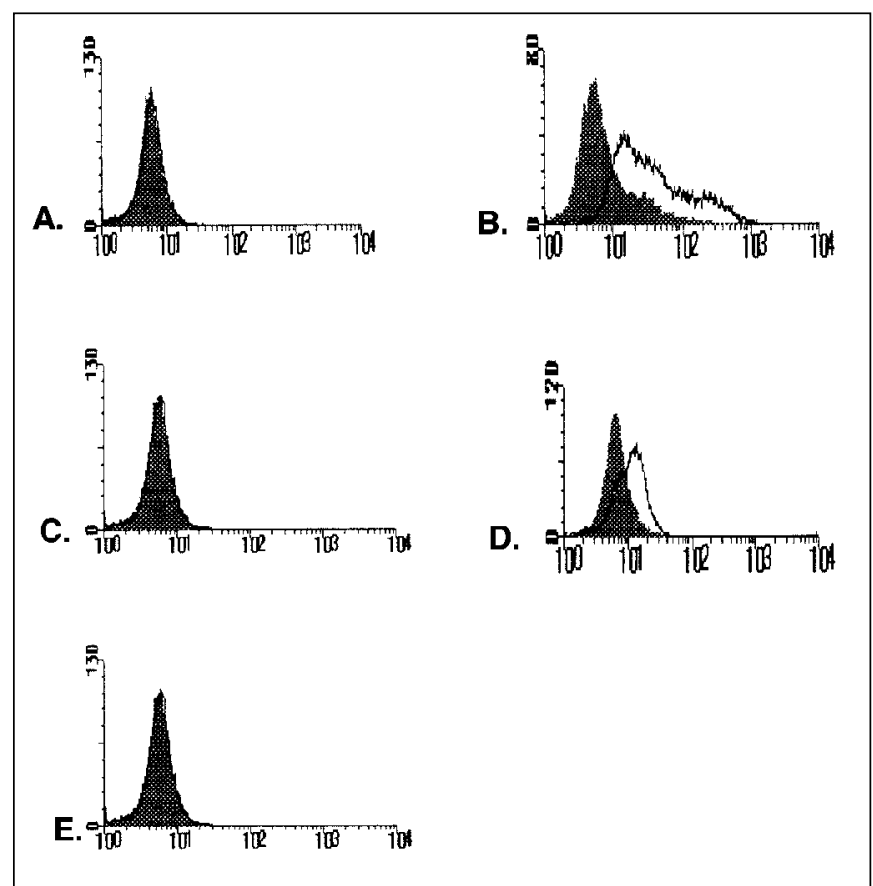

Figure 2: Flow cytometry histograms showing B7-2 expression for (A) Ed147.BT, (B) Ed147.BT-B7-2, (C) Ed147.BT-GM-CSF, (D) Ed147.BT-B7-2/GM-CSF, and (E) Ed147.BT-IL12. Shaded histograms represent background staining with an isotype-matched control antibody. Dark line (unshaded) histograms represent staining with an anti-B7-2 antibody. Shift to the right (in $A$ and $D$ ) represents positive staining.

\section{B. Ed147.PBMC Proliferation}

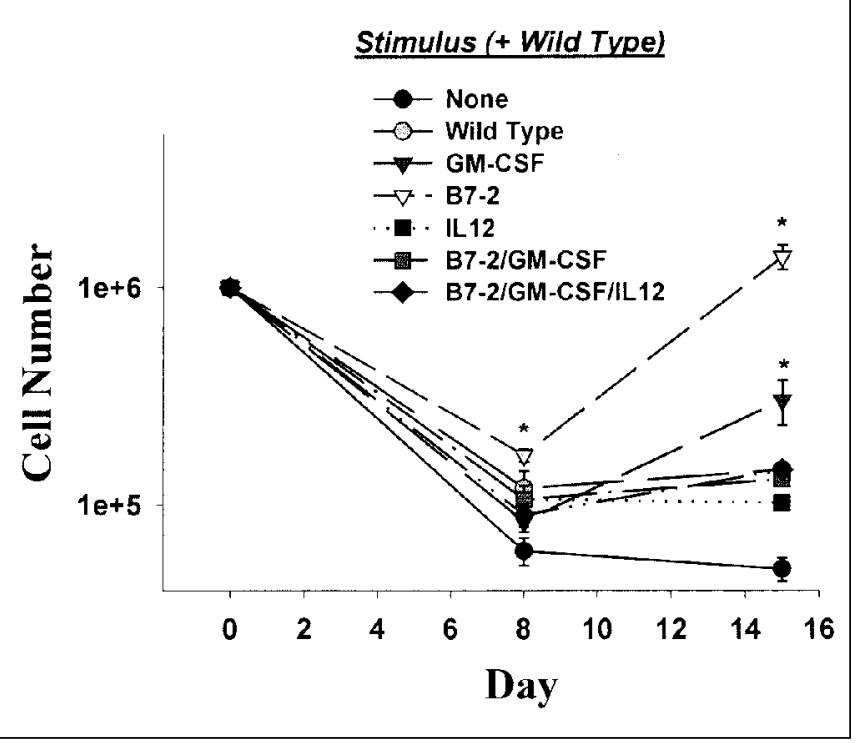

Figure 3: Proliferation curves (cell number per well in 24 well plates) for Ed147.PBMC after primary and secondary rounds of stimulation. (A) Stimulus with gene-transduced cells alone (plus controls with Ed147.BT wild type stimulation or no stimulation). (B) Stimulus with 50\% wild type and $50 \%$ gene-transduced cells. Data points represent means $+/$ - standard deviations for samples counted in triplicate. $*=p<0.05$ compared to wild type-stimulated PBMCs (Dunnett's two-tailed ANOVA). 


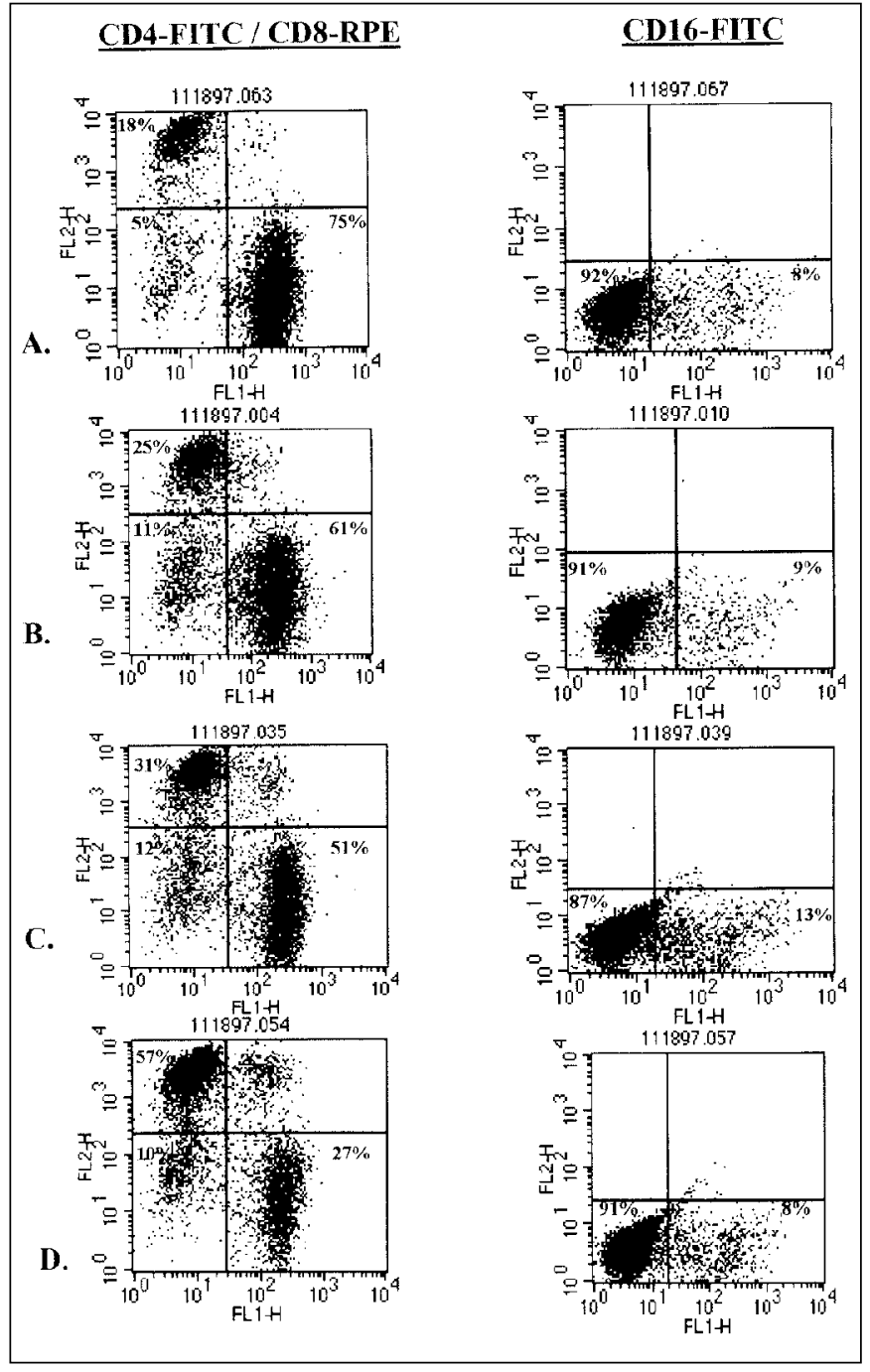

Figure 4: Representative flow cytometry dot plots for $C D 4, C D 8$, and CD16 staining. On the left, CD4+ staining is on the $x$-axis while CD8+ staining is on the y-axis. On the right, CD16+ staining is on the $x$-axis. All dot plots here are from the first experiment (PBMCs stimulated with gene-transduced cells alone). (A) No stimulus. (B) Ed147.BT-wild type. (C) Ed147.BT-IL12. (D) Ed147.BT-B7-2/GM-CSF + Ed147.BT-IL12.

control of an SV40 promotor. This allows for neomycinmediated cell selection after retroviral transduction.

\section{Generation of Replication-Incompetent Retrovirus}

Plasmid DNA for the gene therapy vectors described above was transferred into the retroviral packaging cell line PG13 (American Type Culture Collection) using calcium chloride transfection. This cell line expresses the retroviral packaging genes gag, pol, and env that are absent from the retroviral plasmid vectors. This allows packaging of infectious virus. However, these viruses still lack gag, pol, and env genes, rendering them replication-incompetent. ${ }^{44,45}$ Culture supernatants containing virus were harvested 24 hours after plasmid DNA transfection and stored in $0.5 \mathrm{ml}$ aliquots at $-80^{\circ} \mathrm{C}$ for future use.
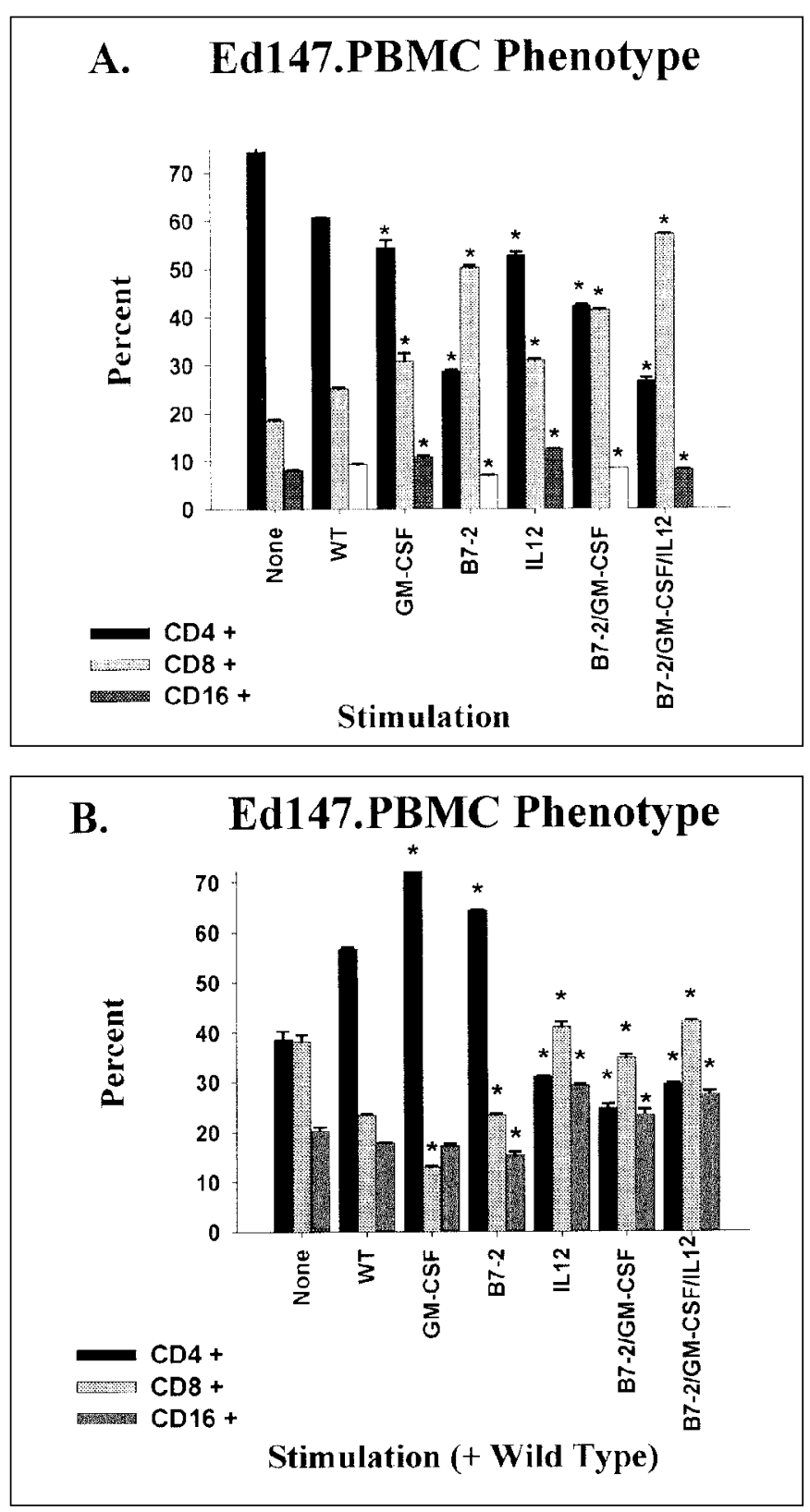

Figure 5: Summary of $\mathrm{CD} 4, \mathrm{CD} 8$, and CD16 staining. Percentage of PBMCs positive for these markers (as opposed to absolute numbers) is shown. (A) Stimulation with gene-transduced cells alone. (B) Stimulation with $50 \%$ wild type $150 \%$ gene-transduced cells. Data points represent mean $+/-S D$ for samples analyzed in duplicate. $*=p<0.05$ compared to wild type-stimulated PBMCs (Dunnett's two-tailed ANOVA).

\section{Retroviral Transduction of Ed147.BT and Cell Selection}

Early passage ( $<5$ passages) Ed147.BT cells were grown to $70 \%$ confluence in T25 flasks. Virus (pLSNB70, pLSNGM1, pLSNIL12, or pLSNBG9) aliquots were thawed at $37^{\circ} \mathrm{C}$. In the presence polybrene $(4 \mu \mathrm{g} / \mathrm{ml})$, Ed147.BT cells were incubated with virus (brought to a final volume of $1.5 \mathrm{ml}$ with fresh culture media) at $37^{\circ} \mathrm{C}, 5 \% \mathrm{CO}_{2}$ for three hours. The same volume of 

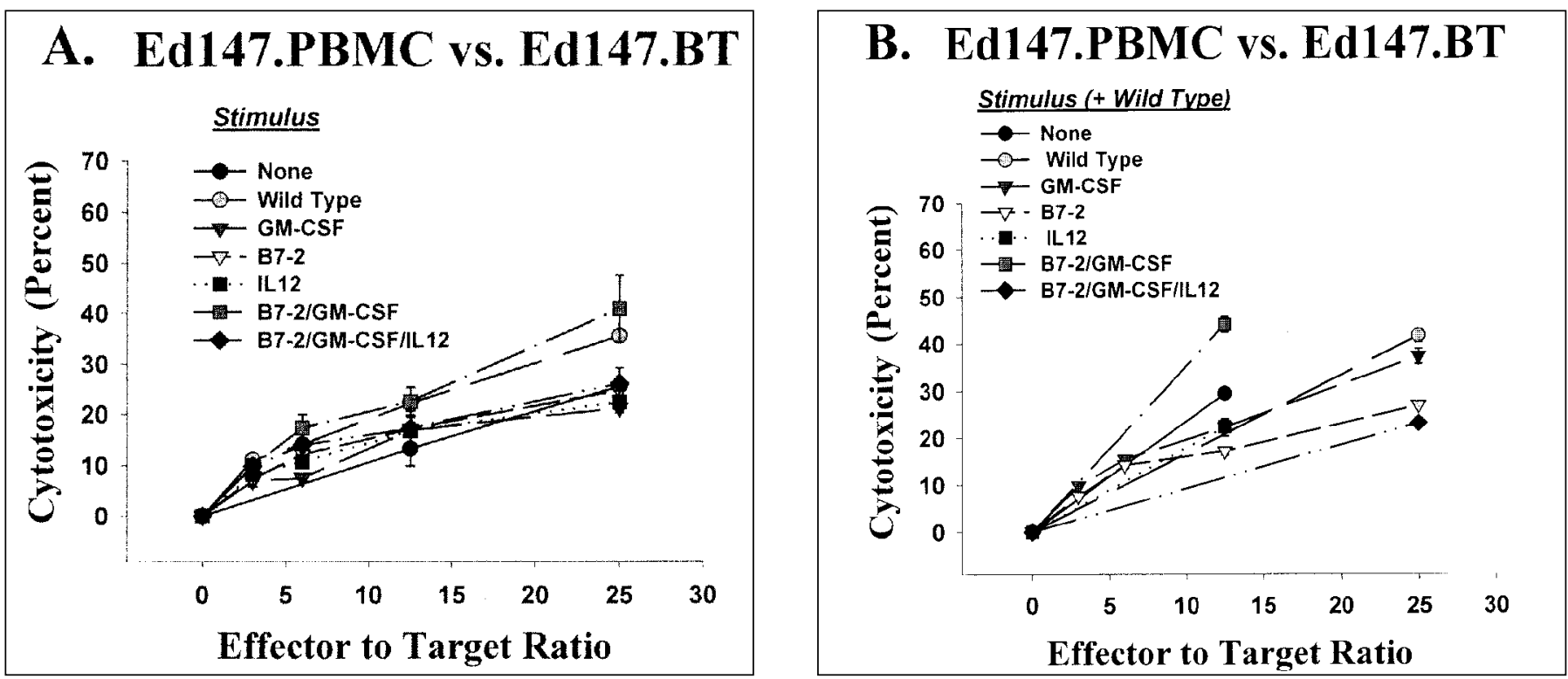

Figure 6: Cytotoxic T lymphocyte ${ }^{51}$ Cr-release assays for Ed147.PBMC vs. autologous glioma cells (Ed147.BT-wild type). A) Stimulation with genetransduced tumor cells alone. B) Stimulation with 50\% wild type $150 \%$ gene-transduced tumor cells. Note that in the second experiment $(\boldsymbol{B})$, cytotoxicity could not be determined at all effector to target cell ratios (3:1, 6:1, 12.5:1, and 25:1) due to reduced PBMC numbers. Data points represent mean +/$S D$ for samples analyzed in triplicate. Statistical significance was determined in (A) but is not shown for clarity (see Results). Statistical significance could not be determined for $(\boldsymbol{B})$.

media and polybrene without virus was used as control. After three hours, a further $3 \mathrm{ml}$ of culture media was added to each flask and they were incubated overnight. Media was changed the next morning.

Twenty-four hours after retroviral transduction, $500 \mu \mathrm{g} / \mathrm{ml}$ of the neomycin analog G418 was added to culture media. Media was changed every two to three days until complete selection had taken place (i.e. all cells in the control flasks were dead). After selection, the cells were cultured in growth media containing reduced concentrations of G418 $(250 \mu \mathrm{g} / \mathrm{ml})$ and allowed to grow to confluence.

\section{Therapeutic Gene Expression Analysis}

B7-2 expression was analyzed by flow cytometry. Ed147.BT cells (with or without transduction) at $70 \%$ confluence were incubated in $0.04 \%$ EDTA in phosphate buffered saline (PBS) for 30 minutes at $37^{\circ} \mathrm{C}$ to detach them from their flasks. They were washed twice in immunofluorescence buffer (2\% fetal bovine serum with $0.02 \%$ sodium azide in PBS) then resuspended in two aliquots of $1 \times 10^{6}$ cells $/ 200 \mu \mathrm{l}$ IF buffer in $1.5 \mathrm{ml}$ Eppendorf tubes. Samples were incubated with either $1 \mu 1$ of anti-B7-2-RPE antibody (Ancell) or $1 \mu \mathrm{l}$ of isotype matched Ig-RPE (Pharmingen) for one hour on ice. After washing two times in IF buffer, cells were then resuspended in $500 \mu$ l of $1 \%$ formaldehyde in PBS. Samples were read immediately on the FL-2 parameter on a Becton-Dickison flow cytometer using CellQuest software.

Commercially available ELISA kits for GM-CSF and IL12 (R + D Systems) were used to determine concentrations of these cytokines in 24 hour conditioned culture media from transduced and wild type Ed147.BT. Cells were counted after harvesting media, enabling GM-CSF and IL12 production to be converted to $\mathrm{ng} / 10^{6}$ cells/day.

\section{Isolation of Peripheral Blood Mononuclear Cells (PBMCs)}

Sixty milliliters of whole blood was obtained from patient Ed147. At the time the blood was drawn, he was receiving dexamethasone $4 \mathrm{mg}$ by mouth four times per day. He was on no other form of chemotherapy.

Whole blood was diluted 1:2 with PBS. This mixture was centrifuged on a density gradient (Ficoll) for 35 minutes at 400 g. Cells that accumulated at the density gradient interface (lymphocyte enriched PBMC) were harvested and washed twice with PBS. These cells were then stored in liquid nitrogen for future use.

\section{PBMC Stimulation}

Peripheral blood mononuclear cells were thawed and cocultured in RPMI with irradiated (200 Gy) Ed147.BT stimulator cells in 24 well plates $\left(5 \times 10^{5}\right.$ stimulator cells/well, effector to stimulator ratio 75:1) in the presence of $20 \mathrm{u} / \mathrm{ml}$ interleukin-2 (IL2) (Boehringer-Mannheim). In the first experimental series, Ed147.BT cells were either wild type, pLSNB70 (B7-2)transduced, pLSNIL12 (IL12)-transduced, pLSNBG9 (B7-2 and GM-CSF)-transduced, or 50\% pLSNBG9 and 50\% pLSNIL12transduced. In addition, some PBMCs were cultured without stimulator cells. In the second experimental series, PBMCs were similarly cultured. However, in this case stimulator cells were a mix of $50 \%$ gene-transduced and $50 \%$ wild type (plus controls with wild type cells alone or no stimulator cells). In all experiments, PBMC were harvested by gentle pipetting after $\sim 1$ 
week (primary stimulation), washed once in RPMI, resuspended, and set up to incubate for another week (secondary stimulation) with fresh stimulator cells. Peripheral blood mononuclear cells were stained with trypan blue and counted with a hemocytometer prior to stimulation and after each stimulation round.

\section{CD4, CD8, and CD16 Expression Testing}

After secondary stimulation, a portion of the PBMCs from each stimulation arm were used for CD4, CD8, and CD16 testing. These were washed twice in IF buffer, then resuspended in four $200 \mu \mathrm{l}$ aliquots. Two aliquots were incubated on ice in the dark for one hour with $5 \mu l$ of anti-CD4-FITC and $5 \mu$ l of antiCD8-RPE (Pharmingen) while two were incubated with $5 \mu 1$ of anti-CD16-FITC (Pharmingen). After this incubation, samples were washed twice in IF buffer and resuspended in 500 of $1 \%$ formaldehyde in PBS. Samples were read immediately using two color staining parameters on a Becton-Dickison flow cytometer and CellQuest software.

\section{Cytotoxic T Lymphocyte Assays}

The remaining PBMCs from each stimulation arm were utilized for cytotoxic T lymphocyte (CTL) assays after the second round of stimulation. Briefly, target cells were incubated with ${ }^{51} \mathrm{Cr}$ for one hour at $37^{\circ} \mathrm{C}$. Ed147.BT (autologous glioma) cells were used as targets. After one hour, cells were washed three times in RPMI then resuspended at $10^{4}$ cells/well in 96 well plates. Effector cells (PBMCs from various stimulation arms) were added to the wells in triplicate at effector to target (E:T) ratios ranging from $3: 1$ to $25: 1$. These were incubated at $37^{\circ} \mathrm{C}$ for four hours, then supernatant was harvested. Radioactive counts for each supernatant were determined on a gamma counter. Target cells in wells without effector cells were used to determine spontaneous release and (after $\mathrm{HCl}$-mediated lysis) total counts. Percent cytotoxicity was determined by the following formula:

$$
\frac{\mathrm{X}-\mathrm{SR}}{\mathrm{TR}-\mathrm{SR}}
$$

where $\mathrm{X}=$ counts in sample, $\mathrm{SR}=$ spontaneous release, and $\mathrm{TR}=$ total release.

\section{RESULTS}

Replication-incompetent retroviral gene therapy vectors encoding B7-2 (pLSNB70), GM-CSF (pLSNGM1), IL12 (pLSNIL12), and B7-2 and GM-CSF (pLSNBG9) were constructed. Schematic plasmid maps appear in Figure 1. Ed147.BT cells showed high levels of therapeutic gene expression after retroviral transduction. Flow cytometry revealed B7-2 expression in Ed147.BT-B7-2 and Ed147.BT-B7-2/GMCSF (1 - 2 orders of magnitude fluorescence shift) but not in Ed147.BT cultures that were not transduced with B7-2 (Figure 2). Mean GM-CSF expression was high (22.345 ng/106 cells/day) for cells transduced with pLSNGM1. GM-CSF expression by pLSNBG9-transduced cells $\left(2.152 \mathrm{ng} / 10^{6}\right.$ cells/day) and IL12 expression by pLSNIL12-transduced cells ( $1.034 \mathrm{ng} / 10^{6}$ cells/day) was somewhat lower. This likely reflects lower expression of genes placed downstream from the IRES (in the case of IL12, production of IL12A becomes the limiting factor).

In both experimental series, PBMC cell numbers decreased during primary stimulation, regardless of stimulation arm
(Figure 3). However, PBMCs exposed to tumor cells expressing B7-2 alone or GM-CSF alone consistently increased in cell number during the second round of stimulation $(p<0.05$ compared to PBMCs exposed to wild type tumor cells, Dunnett's two-tailed ANOVA). In the first experimental series (Figure 3A), PBMCs exposed to tumor cells expressing B7-2 and GM-CSF or B7-2, GM-CSF, and IL12 also significantly increased in number ( $p<0.05$ compared to wild type tumor cells after both rounds of stimulation, Dunnett's two-tailed ANOVA). This was not seen in the second experiment (Figure 3B), possibly due to dilution of transduced cells with wild type stimulators. In general, this pattern of decreased cell numbers after primary stimulation and increased numbers after secondary stimulation with genetransduced cells is consistent with a primary and secondary immune response that is stimulated by the transduced tumor cells. During the primary round, most PBMCs die. However, a small subset presumably undergo primary activation against tumor. During the second round, these memory $\mathrm{T}$ cells get amplified, resulting in an increase in cell number.

Changes in CD4, CD8, and CD16 expression were seen in PBMCs from different stimulation arms (Figure 4, Figure 5). Although there was some variation between the first and second experimental series (particularly for CD4), the pattern for CD8+ and CD16+ cells was fairly consistent. In general, increased percentages of CD8+ cells were seen for PBMCs stimulated with both B7-2 and GM-CSF. Interestingly, increased CD8+ cells were not consistently seen for B7-2 or GM-CSF alone. Increased CD16+ cells were seen when PBMCs were exposed to tumor cells expressing IL12.

While PBMC proliferation and cell surface marker expression generally correlated with the genes transferred to stimulator cells, results of anti-tumor cytotoxicity testing were somewhat unexpected. When PBMC were stimulated by genetransduced tumor cells alone (Figure 6A), only B7-2 and GMCSF transduced tumor cells stimulated PBMCs with more cytotoxic activity against autologous glioma cells than stimulation with wild type tumor alone. Furthermore, although this was statistically significant at effector to target ratios of $6: 1$ and 25:1 ( $\mathrm{p}<0.05$, Dunnett's two-tailed ANOVA), the magnitude of the increase was minimal. All remaining stimulation arms resulted in PBMCs with reduced cytotoxic activity compared to wild type tumor stimulated PBMCs $(\mathrm{p}<0.05$, Dunnett's twotailed ANOVA). In other words, despite stimulating appropriate proliferation and phenotypic changes in PBMCs, autologous glioma cells expressing GM-CSF, B7-2, and/or IL12 appeared less effective at stimulating anti-tumor cytotoxic lymphocytes than wild type tumor cells.

One possible explanation for the lack of specific cytotoxic $\mathrm{T}$ lymphocyte activity despite other evidence for lymphocyte proliferation may relate to the retroviral gene transfer method. This involves cell selection for the antibiotic G418 that may result in antigenically distinct subclones that are different from wild type cells. To assess for this we performed a second experimental series in which PBMCs were stimulated with mixtures of $50 \%$ wild type and $50 \%$ gene-transduced cells. Peripheral blood mononuclear cell proliferation was somewhat reduced in this case (Figure 3B), as is consistent with a $50 \%$ reduction in immunostimulatory gene exposure. Unfortunately, this reduced the number of PBMCs available for CTL assays. 
Not all effector to target cell ratios could be tested for each stimulation arm (Figure 6B) and this prevented accurate statistical analysis. Nevertheless, it appears that stimulation with $50 \%$ wild type and 50\% B7-2/GM-CSF-transduced cells produced markedly higher cytotoxicity than any other stimulation. Of note, wild type tumor cells alone still appeared to induce greater anti-tumor cytotoxicity than any other stimulation except 50\% wild type and 50\% B7-2/GM-CSF-transduced cells.

\section{DisCUSSION}

In our previous studies of anti-glioma immunogene therapy, we demonstrated that vaccinating allogeneic human lymphocytereconstituted severe combined immunodeficiency/bg mice with glioma cells genetically modified to express B7-2 and GM-CSF resulted in a systemic anti-tumor immune response that inhibited pre-existing wild type tumor growth at distant sites. ${ }^{19}$ A major drawback of this study was its allogeneic nature. In the present study, this problem was addressed by examining the ability of genetically modified human glioma cells to stimulate anti-tumor lymphocytes from autologous PBMCs. In addition, we examined the effects of a third gene, IL12, and attempted to ascertain if there are any synergistic affects from the use of combinations of these genes.

Exposure to glioma cells expressing GM-CSF, B7-2, and/or IL12 clearly has complex effects upon autologous PBMCs. Exposure to cells expressing B7-2 or GM-CSF alone appears to strongly stimulate proliferation compared to wild type cells or no stimulus at all (Figure 3). Pure populations of cells expressing combinations of GM-CSF, B7-2, and/or IL12 also appear to stimulate PBMC proliferation (Figure 3A). Increased proliferation was not seen, however, for PBMCs exposed to mixtures of $50 \%$ wild type and $50 \%$ cells expressing combinations of GM-CSF, B7-2, and/or IL12 (Figure 3B). This lack of proliferation may simply represent a decrease in "dose" of gene transduced cells in the second experiment. In general, a pattern of increased PBMC proliferation is seen for cells exposed to immunostimulatory gene-transduced autologous glioma. This appears to be greatest for B7-2 alone, followed by GM-CSF alone, then by combinations of GM-CSF, B7-2, and/or GM-CSF.

Phenotypic changes in PBMC populations after exposure to immunostimulatory gene-transduced glioma are also evident. Some nonspecific variations can be seen between absolute percentages of cells expressing various lymphocyte markers between the two experimental series (Figure 5A and 5B). For example, percentages of CD4+, CD8+, and CD16+ cells among PBMCs receiving no specific stimulation differ considerably between the two series $(\mathrm{p}<0.005$ for all three surface molecules by students' $\mathrm{T}$ test). However, increases in CD16+ cells are consistently seen among PBMCs exposed to IL12-transduced cells (alone or in combination with other genes). Increases in CD8+ cells are consistently seen for PBMCs exposed to combinations of B7-2 and GM-CSF or B7-2, GM-CSF, and IL12. These findings are consistent with the known role of IL12 in stimulating NK cells (CD16+) ${ }^{26}$ and our hypothesized role of combinations of these genes in stimulating increased anti-tumor cytotoxic T cells (CD8+).

Increased proliferation and increased CD8+ and CD16+ cells among PBMCs exposed to gene-transduced glioma were consistent with our expectations. However, our initial CTL assays (Figure 6A) showed that PBMCs stimulated with genetransduced glioma do not have increased cytotoxic activity against autologous glioma compared to PBMCs stimulated with wild type glioma. At first glance, this unexpected result seems incompatible with the observed effects on PBMC proliferation and phenotype.

Several explanations for this result were considered. Occult mycoplasma infection may have altered immune responses. Testing our cell cultures for mycoplasma ruled out this possibility (data not shown). It was also possible that our in vitro system lacked proper antigen presenting cells. This could explain why our responses seemed nonspecific. This is unlikely as PBMCs contain significant proportions of monocyte/ macrophage cells that could act as professional antigen presenting cells. Choosing B7-2 as a costimulatory molecule may have contributed to the lack of specific cytotoxic responses. In mice, exposure to B7-1 is required in addition to B7-2 for cytotoxic $\mathrm{T}$ cell precursors to acquire cytolytic activity. ${ }^{46}$ Possibly, we did not see specific anti-tumor cytotoxic activity because we exposed PBMCs to tumor cells expressing high levels of B7-2 in the absence of B7-1. However, this does not explain the lack of specific anti-tumor cytotoxicity for PBMCs stimulated with GM-CSF or IL12-transduced tumor alone (in the absence of B7-2).

Intrinsic lymphocyte abnormalities may have contributed to the lack of specific anti-tumor cytotoxicity. Dexamethasone, commonly administered to glioma patients, can markedly reduce anti-glioma immune responses. ${ }^{47}$ However, patient Ed147 was not receiving dexamethasone when he donated blood for these experiments. Other lymphocyte proliferation abnormalities have

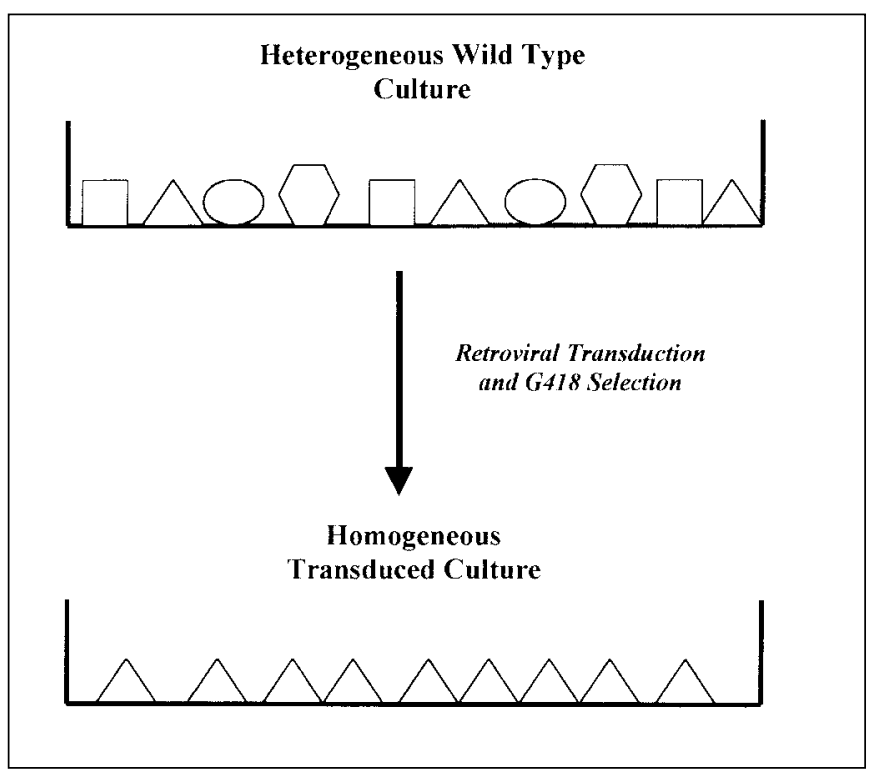

Figure 7: Schematic demonstrating heterogeneous nature of early passage wild type culture. Different cells, although all neoplastic and derived from the same tumor, may express different tumor antigens. Retroviral transduction may result in selection of a subclone with a markedly different antigenic library than the bulk of the wild type culture. However, this subclone presumably expresses tumor antigens that are present in at least some portion of the tumor in situ. 
been described in glioma patients, ${ }^{48,49}$ but impaired proliferation was not seen in our experiments (Figure 3). Some intrinsic lymphocyte abnormalities reported in nonglioma cancers may be compatible with our results. Tumor-associated antigen-specific CD8+ $\mathrm{T}$ cells isolated from melanoma patients may have an unusual phenotype in which they are functionally inactive (unable to lyse melanoma cells) despite having many of the hallmarks of effector T-cells. ${ }^{50}$ If one accepts that gliomaspecific or glioma-associated antigens do exist, ${ }^{51,52}$ it is possible that specific $\mathrm{T}$ cell clones generated in response to these antigens would have a similar phenotype (i.e. suggestive of cytotoxic $\mathrm{T}$ killers but functionally unable to lyse glioma cells). This is compatible with our initial results (Figure 6A) but cannot be verified in the absence of glioma-associated antigen-specific $\mathrm{T}$ cell clones.

However, another possible explanation for lack of cytotoxicity in our experiments exists that can be tested. Antibiotic-mediated cell selection during retroviral transduction of glioma cells may have effects that diminish anti-tumor responses. Early $(<5)$ passage glioma cultures were used for retroviral transduction. Unlike established, immortalized cell lines, these cultures are very heterogeneous. When G418 was used to select cells that had been transduced, it is possible that the resulting subclones had a different antigenic spectrum than the wild type cultures. This is shown schematically in Figure 7. Stimulating PBMCs with these subclones may generate CTLs with limited activity against the more antigenically diverse wild type cultures. It appears that this final possibility is correct. When PBMCs were stimulated with mixtures of 50\% wild type cells $/ 50 \%$ gene-transduced cells, it was possible to generate lymphocytes with increased anti-tumor cytotoxicity compared to PBMCs stimulated with wild type cells alone (Figure 6B). Interestingly, this effect was only seen for the combination of wild type with B7-2/GM-CSF-transduced cells. Any combination of wild type cells with cells expressing a single immunostimulatory gene or a combination of all three genes (B7-2, GM-CSF, and IL12) resulted in reduced anti-tumor cytotoxicity compared to PBMCs stimulated with wild type cells alone.

Therefore, it appears that cells expressing B7-2 and GM-CSF synergize with wild type cells to induce anti-tumor immunity. Any other combination of B7-2, GM-CSF, IL12, and wild type cells does not induce greater anti-tumor cytotoxicity in PBMCs than wild type tumor alone. Wild type tumor cells are apparently necessary to provide a greater tumor antigen library for immunologic stimulation. Decreased anti-tumor cytotoxicity among PBMCs stimulated with a combination of wild type and B7-2, GM-CSF, and IL12-expressing cells is interesting. The reasons that this combination did not yield the greatest degree of anti-tumor cytotoxicity (as we had expected) are not immediately clear. However, it may simply represent a case of "too much of a good thing". In other words, introducing too many signals may have resulted in hyperstimulation and subsequent anergy of anti-tumor lymphocytes.

While it is likely that anti-tumor immunity could be increased in clinical trials by adding wild type tumor cells to the vaccine, this may not be advisable initially. The few clinical reports available on immunogene therapy for patients harboring intracranial tumors suggest that these patients developed significant intracranial edema after vaccination. ${ }^{53,54}$ Therefore, it may be safest to initiate antiglioma immunogene therapy trials using only gene-transduced cells at first. Only after safety has been established using these vaccines will it be safe to proceed with trials of vaccination using mixtures of wild type and genetransduced cells.

Immunogene therapy is a promising experimental treatment modality for gliomas. This study suggests that B7-2/GM-CSFtransduced glioma cells synergize with wild type cells to stimulate autologous anti-tumor lymphocytes. This effect was not seen if wild type tumor cells were not present as stimulators in addition to immunostimulatory gene-transduced cells. Despite this, it may be prudent to carry out safety studies with genetransduced alone vaccines prior to proceeding with combinations including wild type genes.

\section{ACKNOWLEDGEMENTS}

This work has been presented in part at the Congress of Neurological Surgeons in Seattle, Washington in October 1998 and was supported in part by the University of Alberta Hospital Foundation and the Foote Foundation. Dr. Parney is an Alberta Heritage Foundation for Medical Research Clinical Fellow.

\section{REFERENCES}

1. Kornblith PK, Welch WC, Bradley MK. The future therapy for glioblastoma. Surgical Neurol 1993; 39: 538-543.

2. Yung WKA. New approaches to molecular therapy of brain tumors. Curr Op Neurol 1994; 7: 501-505.

3. Ettinghausen SE, Rosenberg SA. Immunotherapy and gene therapy of cancer. Adv Surg 1995; 28: 223-254.

4. Parney IF, Hao C, Petruk KC. Glioma immunology and immunotherapy: a review. Neurosurgery 2000; 46: 778-792.

5. Parney IF, Farr-Jones MA, Chang L-J, Petruk KC. Human glioma immunobiology in vitro: implications for immunogene therapy. Neurosurgery 2000; 46: 1169-1178.

6. Siepl C, Bodmer S, Frei K, et al. The glioblastoma derived T-cell suppressor factor/transforming growth factor beta 2 inhibits Tcell growth without affecting the interaction of interleukin-2 with its receptor. Eur J Immunol 1988; 18: 593-600.

7. Kuppner M, Hamou M, Sawamura Y, Bodmer S, de Tribolet N. Inhibition of lymphocyte function by glioblastoma-derived transforming growth factor beta 2 . J Neurosurg 1989; 71: 211217.

8. Bodmer S, Strommer K, Frei K, et al. Immunosuppression and transforming growth factor beta in glioblastoma: preferential production of transforming growth factor beta 2. J Immunol 1989; 143: 3222-3229.

9. Fontana A, Kristensen F, Dubs R, Gemsa D, Weber E. Production of prostaglandin $\mathrm{E}$ and interleukin-1 like factor by cultured astrocytes and C6 glioma cells. J Immunol 1982; 129: 24132419.

10. Sawamura $\mathrm{Y}$, Diserens A-C, de Tribolet N. In vitro Prostaglandin $\mathrm{E}_{2}$ production by glioblastoma cells and its effect on interleukin-2 activation of oncolytic lymphocytes. J Neurooncol 1990; 9: 125130.

11. Hao C, Parney IF, Ramsay DA, et al. Cytokine and cytokine receptor mRNA expression in human glioblastoma tumors and cell lines. Acta Neuropathol (Berl) 2001; In Press.

12. Plate KH, Risau W. Angiogenesis in malignant gliomas. Glia 1995; 15: 339-347.

13. Wesseling P, Ruiter DJ, Burger PC. Angiogenesis in brain tumors; pathological and clinical aspects. J Neurooncol 1997; 32: 253265.

14. Grabilovich DI, Chen HL, Girgis KR, et al. Production of vascular endothelial growth factor by human tumors inhibits the 
functional maturation of dendritic cells. Nature Med 1996; 2: 1096-1103.

15. Fakhrai H, Dorigo O, Shawler DL, et al. Eradication of established intracranial rat gliomas by transforming growth factor beta antisense gene therapy. PNAS 1996; 93: 2909-2914.

16. Dranoff G, Jaffee E, Lazenby A, et al. Vaccination with irradiated tumor cells engineered to secrete murine granulocytemacrophage colony-stimulating factor stimulates potent, specific and long lasting anti-tumor immunity. PNAS 1993; 90: 35393543.

17. Sampson JH, Archer GE, Ashley DM, et al. Subcutaneous vaccination with irradiated, cytokine-producing tumor cells stimulates CD8+ cell-mediated immunity against tumors located in the "immunologically privileged" central nervous system. PNAS 1996; 93: 10399-10404.

18. Yu JS, Burwick JA, Dranoff G, Breakefield XO. Gene therapy for metastatic brain tumors by vaccination with granulocytemacrophage colony-stimulating factor-transduced tumor cells. Hum Gene Ther 1997; 8: 1065-1072.

19. Parney IF, Petruk KC, Zhang C, et al. GM-CSF and B7-2 combination immunogene therapy in an allogeneic hu-PBL$\mathrm{SCID} /$ beige mouse-human glioblastoma multiforme model. Hum Gene Ther 1997; 8: 1073-1085.

20. Parney IF, Farr-Jones MA, Koshal A, Chang L-J, Petruk KC. Human brain tumor cell culture characterization following immunostimulatory gene transfer. Neurosurgery 2002; In press.

21. Gainer AL, Young ATL, Parney IF, Petruk KC, Elliott JF. Gene-gun transfection of human glioma and melanoma cell lines with genes encoding human IL-12 and GM-CSF. J Neurooncol 2000; 47: 2330.

22. Lieshcke G, Burgess A. Granulocyte colony-stimulating factor and granulocyte-macrophage colony-stimulating factor (part I). NEJM 1992; 327: 28-35.

23. Aglietta M, Piacibello W, Pasquino P, et al. Rationale for the use of granulocyte-macrophage colony-stimulating factor. Semin Oncol 1994; 21: 5-9.

24. Engelhard M, Brittinger G. Clinical relevance of granulocytemacrophage colony-stimulating factor. Semin Oncol 1994; 21: 14.

25. Hanada K, Tsunoda R, Hamada H. GM-CSF-induced in vivo expansion of splenic dendritic cells and their strong costimulation activity. J Leukocyte Biol 1996; 60: 181-190.

26. Brunda MJ. Interleukin-12. J Leukocyte Biol 1994; 55: 280-288.

27. Tahara H, Lotze MT. Antitumor effects of interleukin-12 (IL-12): applications for the immunotherapy and gene therapy of cancer. Gene Ther 1995; 2: 96-106.

28. Tahara H, Lotze MT, Robbins PD, Storkus WJ, Zitvogel L. Clinical Protocol: IL-12 gene therapy using direct injection of tumors with genetically engineered autologous fibroblasts. Hum Gene Ther 1995; 6: 1607-1624.

29. Li Y, McGowan P, Hellstrom I, Hellstrom KE, Chen L. Costimulation of tumor-reactive CD4+ and CD8+ T lymphocytes by $\mathrm{B} 7$, a natural ligand for $\mathrm{CD} 28$, can be used to treat established mouse melanoma. J Immunol 1994; 153: 421-427.

30. Freeman G, Gribben J, Baussioties V, et al. Cloning of B7-2: a CTLA-4 counter-receptor that costimulates human T-cell proliferation. Science 1993; 262: 909-911.

31. Chen L, Ashe S, Brady W, et al. Costimulation of antitumor immunity by the B7 counterreceptor for the $\mathrm{T}$ lymphocyte molecules CD28 and CTLA-4. Cell 1992; 71: 1093-1102.

32. Lanier L, O'Fallon S, Somoza C, et al. CD80 (B7) and CD86 (B70) provide similar costimulatory signals for $\mathrm{T}$ cell proliferation, cytokine production, and generation of CTL. J Immunol 1995; 154: $97-105$

33. Mondino A, Jenkins MK. Surface proteins involved in $\mathrm{T}$ cell costimulation. J Leukocyte Biol 1994; 55: 805-815.

34. June C, Bluestone J, Nadler L. The B7 and CD28 receptor families. Immunol Today 1994; 15: 321-331.
35. Yang G, Hellstrom KE, Hellstrom I, Chen L. Antitumor immunity elicited by tumor cells transfected with B7-2, a second ligand for CD28/CTLA-4 costimulatory molecules. J Immunol 1995; 154: 2794-2800.

36. Plumas J, Chaperot L, Jacob M-C, et al. Malignant B lymphocytes from non-Hodgkin's lymphoma induce allogeneic proliferative and cytotoxic $\mathrm{T}$ cell responses in primary mixed lymphocyte cultures: an important role of costimulatory molecules CD80 (B7-1) and CD86 (B7-2) in stimulation by tumor cells. Eur J Immunol 1995; 25: 3332-3341.

37. Glick RP, Lichtor T, Mogharbel A, Taylor CA, Cohen EP Intracerebral versus subcutaneous immunization with allogeneic fibroblasts genetically engineered to secrete interleukin- 2 in the treatment of central nervous system glioma and melanoma. Neurosurgery 1997; 41: 898-907.

38. Glick RP, Lichtor T, Kim TS, Ilangovan S, Cohen EP. Fibroblasts genetically engineered to secrete cytokines suppress tumor growth and induce antitumor immunity to a murine glioma in vivo. Neurosurgery $1995 ; 36$ : 548-555.

39. Auer RN, Del Maestro RF, Anderson R. A simple and reproducible experimental in vivo glioma model. Can J Neurol Sci 1981; 8: 325-331.

40. Hamilton D, McKean JDS, Tulip J, Boisvert D, Cummins J. In vitro photoradiation therapy of rat $9 \mathrm{~L}$ gliosarcoma. J Neurosurg 1986; 64: 775-779.

41. Krushelnycky BW, Farr-Jones MA, Mielke B, et al. Development of a large-animal human brain tumor xenograft model in immunosuppressed cats. Cancer Res 1991; 51: 2430-2437.

42. Parney IF, Farr-Jones MA, Petruk KC. Improved technique for establishing short term human brain tumor cultures. J Neurooncol 1999; 43: 1-10.

43. Robinson D, Elliott JF, Chang LJ. Retroviral vector with a CMVIE/HIV-TAR hybrid LTR gives high basal expression levels and is upregulated by HIV-1 Tat. Gene Ther 1995; 2: 269-278.

44. Miller AD, Buttimore C. Redesign of retrovirus packaging cell lines to avoid recombination leading to helper virus production. Molec Cell Biol 1986; 6: 2895-2902.

45. Miller AD, Miller DG, Garcia JV, Lynch CM. Use of retroviral vectors for gene transfer and expression. Meth Enzymol 1993; 217: 581-599.

46. King C, Hoenger RM, Cleary MM, et al. Interleukin-4 acts at the locus of the antigen-presenting dendritic cell to counter-regulate cytotoxic CD8+ T-cell responses. Nature Med 2001; 7: 206-214.

47. Badie B, Schartner JM, Paul J, et al. Dexamethasone-induced abolition of the inflammatory response in an experimental glioma model: a flow cytometry study. J Neurosurg 2000; 93: 634-639.

48. Roszman T, Elliott L, Brooks W. Modulation of T-cell function by gliomas. Immunol Today 1991; 12: 370-374.

49. Morford LA, Elliott LH, Carlson SL, Brooks WH, Roszman TL. T cell receptor-mediated signalling is defective in T cells obtained from patients with primary intracranial tumors. J Immunol 1997; 159: 4415-4425.

50. Lee PP, Yee C, Savage PA, et al. Characterization of circulating T cells specific for tumor-associated antigens in melanoma patients. Nature Med 1999; 5: 677-685.

51. Kurpad SN, Zhao X-G, Wikstrand CJ, et al. Tumor antigens in astrocytic gliomas. Glia 1995; 15: 244-256.

52. Lampson LA. Immunobiology of brain tumors: antigens, effectors, and delivery to sites of microscopic tumor in the brain. In: Black PM, Loeffler (Eds.), Cancer of the Nervous System. Blackwell Science, Inc., 1997.

53. Sobol RE, Fakhrai H, Shawler D, et al. Interleukin-2 gene therapy in a patient with glioblastoma. Gene Ther 1995; 2: 164-167.

54. Ellem KAO, O'Rourke MGE, Johnson GR, et al. A case report: immune responses and clinical course of the first human use of granulocyte-macrophage colony-stimulating factor-transduced autologous melanoma cells for immunotherapy. Cancer Immunol Immunother 1997; 44: 10-20. 